\title{
A COVID-19 e sua Influência no Comportamento e Fruição das Praias Marítimas Urbanas de Balneário Camboriú, Santa Catarina, Brasil
}

\author{
Maria Emília Martins da Silva Garbuio \\ Eduardo Augusto Werneck Ribeirob
}

\begin{abstract}
Resumo
É consenso mundial que a incidência da pandemia do novo Coronavírus tem afetado de forma inequívoca o turismo em praticamente todos os países do globo, com perdas inestimáveis e sem precedentes. O lockdown praticado por muitas cidades tem sido a alternativa para restringir o rápido contágio. Espaços públicos como parques e praias urbanas também adotaram esta medida, na tentativa de minimizar a aglomeração de pessoas. Diante desse cenário, pretendeu-se identificar como a Covid-19 tem influenciado o comportamento, percepções e expectativas de usuários das praias urbanas em Balneário Camboriú. Adotou-se a pesquisa por questionário com residentes do município, com uma amostra de 129 informantes, cuja análise se deu por meio da comparação entre os dados. Os resultados demonstraram que os moradores têm acatado as orientações para se manterem distantes da praia e orla, espaços estes que já faziam parte de seu cotidiano. O sentimento mais evidenciado no grupo foi a insegurança em relação à Covid-19 e seus diferentes impactos sobre a cidade como destino turístico.
\end{abstract}

Palavras-chave: Balneário Camboriú. Turismo. Pandemia. Elasticidade da demanda. Zona costeira.

\begin{abstract}
COVID-19 and its Influence on the Behaviour and Enjoyment of Urban Maritime Beaches in Balneário Camboriú, Santa Catarina, Brazil

It is a worldwide consensus that the incidence of the new coronavirus pandemic has unequivocally affected tourism in practically all countries of the globe, with priceless and unprecedented losses. The lockdown practiced by many cities has been the alternative to restrict the fast contagion. Public spaces such as parks and urban beaches have also adopted this measure, in an attempt to minimize the crowding of people. Given this scenario, it was intended to identify how Covid-19 has influenced the behavior, perceptions and expectations of users of urban beaches in Balneário Camboriú, Santa Catarina. The survey with residents of the municipality was adopted, with a sample of 129 informants, whose analysis was done by comparing the data. The results showed that the residents have followed the guidelines to stay away from the beach and shore, spaces that were already part of their daily lives. The most evident feeling was the insecurity regarding Covid-19 and its different impacts on the tourist city.
\end{abstract}

Keywords: Balneário Camboriú. Tourism. Pandemic. Elasticity of demand. Coast.

a. Doutora em Engenharia e Gestão do Conhecimento pela Universidade Federal de Santa Catarina (UFSC), Florianópolis, Santa Catarina, Brasil. Docente no curso superior de Tecnologia em Gestão de Turismo e no curso técnico em Hospedagem do Instituto Federal Catarinense (IFC), Sombrio, Santa Catarina, Brasil. E-mail: maria.martins@ifc.edu.br

b. Pós-doutor pela Universidade Estadual Paulista (UNESP), Presidente Prudente, SP, Brasil. Docente no Mestrado em Tecnologia e Ambiente do Instituto Federal Catarinense (IFC), Araquari, SC, Brasil. E-mail: eduardo.ribeiro@ifc.edu.br 


\section{Resumen \\ COVID-19 y su Influencia en el Comportamiento y Disfrute de las Playas Marítimas Urbanas de Balneário Camboriú, Santa Catarina, Brasil}

Es un consenso mundial que la incidencia de la pandemia del nuevo coronavirus ha afectado inequívocamente el turismo en prácticamente todos los países del mundo, con pérdidas invaluables y sin precedentes. El bloqueo practicado por muchas ciudades ha sido la alternativa para restringir el contagio rápido. Los espacios públicos como parques y playas urbanas también han adoptado esta medida, en un intento de minimizar la aglomeración de personas. Dado este escenario, se pretendía identificar cómo Covid-19 ha influido en el comportamiento, las percepciones y las expectativas de los usuarios de playas urbanas en Balneário Camboriú, Santa Catarina. Se adoptó la encuesta con los residentes del municipio, con una muestra de 129 informantes, cuyo análisis se realizó comparando los datos. Los resultados mostraron que los residentes han seguido las pautas para mantenerse alejados de la playa y la costa, espacios que ya formaban parte de su vida cotidiana. El sentimiento más evidente fue la inseguridad con respecto a Covid-19 y sus diferentes impactos en la ciudad.

Palabras clave: Balneário Camboriú. Turismo. Pandemia. Elasticidad de la demanda. Costa.

\section{CONTEXTUALIZAÇÃo}

0 turismo tem tido um crescimento econômico exponencial e significativo nas últimas décadas (OECD, 2020), excetuando-se aqueles períodos marcados por crises internacionais, como os atentados de 11 de setembro de 2001 (Goodrich, 2002; Blake \& Sinclair, 2020) e a crise econômica mundial de 2008 (Ritchie et al., 2010). Esses acontecimentos incidiram, de forma abrupta e temporária, na desaceleração drástica dos 98 setores que integram a cadeia produtiva do turismo, com relevância para o setor aéreo e de hospedagem. (Blake \& Sinclair, 2020). Nos meses que precederam esses eventos, parte da população mundial se conteve em diminuir ou restringir suas viagens, especialmente para países norte-americanos, impactando negativamente os gastos com turismo. (Blake \& Sinclair, 2020). Ambas as crises provocaram uma retração no turismo de aproximadamente $20 \%$ (Blake \& Sinclair, 2020; Zielinski \& Botero, 2020), sendo atualmente um fato histórico que ainda repercute para o desenvolvimento de políticas públicas, econômicas e de segurança, das nações mais atingidas.

0 ano de 2020 trouxe consigo um visitante inesperado para todos os destinos turísticos: o novo Coronavírus Sars-Cov-2, doravante, Covid-19. Ele se remete ao 30 de janeiro de 2020 na cidade de Wuhan, na China, data em que a Organização Mundial da Saúde (OMS) publicou a Declaração de Emergência em Saúde Pública de Importância Internacional, (Malloy-Diniz et al. 2020; Cuccinotta \& Vanelli, 2020). Esta é considerada a maior emergência de saúde da história recente (Zhang et al., 2020, Gössling, Scott, \& Hall, 2020), acompanhada da interrupção mais severa da economia global desde a Segunda Guerra Mundial (Gössling et al., 2020), uma vez que o contágio pelo vírus se espalhou por todo o mundo. No Brasil, a Emergência em Saúde Pública de Importância Nacional (ESPIN) em decorrência da Covid-19 foi declarada por meio da Portaria n ${ }^{\circ} 188$ / GM/MS, em 3 de fevereiro de 2020 (Malloy-Diniz et al., 2020).

O site do Ministério da Saúde (2020) intitulado Painel Coronavírus contabilizou até o dia 12 de novembro de 2020, o acumulado de 5.590.025 de casos e 
23.976.781 mortes $^{1}$ no Brasil. Segundo a OMS/OPAS - Organização Pan-Americana da Saúde (2020), "o distanciamento social é adotado como medida aplicada a entornos sociais específicos, ou à sociedade em sua totalidade, para reduzir a velocidade de propagação da Covid-19.

A Organização Mundial do Turismo - OMT (2020) declarou que "esse é de longe o pior resultado da série histórica do turismo internacional desde 1950, e põe um fim abrupto em um período de 10 anos de crescimento sustentado desde a crise financeira de 2009". Zielinski e Botero (2020) explicam que, devido à importância econômica do turismo, o impacto da Covid-19 nas indústrias relacionadas a viagens tem sido estudado em muitos países e destinos. Diante dos fatos, a resiliência declarada pela OMT para a atividade turística está desafiada (Hall, Scott, \& Gössling, 2020).

Dado o cenário atual global, os destinos turísticos mundiais tenderão a sofrer alterações profundas e com consequências nefastas para a economia e, quem sabe, para a sociabilidade dos indivíduos, sobretudo aquela que incide sobre os espaços públicos de maior envolvimento social, como as praças, parques e praias (incluindo a orla marítima), e que se traduz como importante critério de escolha por um destino de viagem/visitação (Zielinski \& Botero, 2020). Orla marítima e praias promovem bem-estar e conexão com a natureza, mas, no momento de uma pandemia cujo contato com o vírus se dá pelo ambiente social, estas aparentam constituir risco iminente de contágio pelo ar, pela areia e pela água para o Coronavírus. (Zielinski \& Botero, 2020).

Observando esta realidade, propõe-se uma questão de pesquisa aos residentes do município de Balneário Camboriú, Santa Catarina - Brasil: - Como tem sido o comportamento das pessoas nos espaços públicos durante a pandemia do novo Coronavírus? 0 turismo se manterá resiliente após as orientações de lockdown, também nas praias? Que sentimentos têm se manifestado nos autóctones da cidade costeira turística de Balneário Camboriú, neste período de pandemia?

Indagações como essas se mostram importantes para a codificação de informações acerca de comportamentos, percepções de risco e expectativas dos consumidores habitués de praias urbanas de destinos turísticos, tomando como case um destino de sol e praia proeminente do sul do Brasil. É sabido que componentes da cadeia produtiva do turismo de todo o mundo têm sofrido com perdas indeléveis, sejam humanas, financeiras e sociais, somando consequências irreversíveis para suas atividades a médio e longo prazos (Zielinski \& Botero, 2020; Blake \& Sinclair, 2020; Gössling et al., 2020) salvo considerar, todavia, os espaços naturais que, devido ao isolamento social, têm sofrido alterações bastante positivas, no tocante à recuperação biofísica do ambiente degradado e visualmente uma melhoria repentina da qualidade ambiental (Botero, Mercadé, Cabrera, \& Bombana, 2020; Polette, 2020).

Identificar comportamentos, percepções e expectativas de um grupo de pessoas acerca de um dado fenômeno, atípico ou não, colabora de forma notável para a assertividade na tomada de decisões de gestores locais, visto que o conhecimento resultante da experiência individual e coletiva deve ser compreendido para desmistificar especulações subjetivas e apoiar ações de retomada da economia e interação

1. Os dados atualizados podem ser acessados em no Painel Coronavírus, disponível no link: https://covid.saude.gov.br/. 
socioambiental de forma consciente e realista. Segundo Malloy-Diniz et al. (2020, p. 2), em cenários pairados pela incerteza e novidade, é importante criar diretrizes com as melhores informações disponíveis para pautar a atuação de profissionais, tomadores de decisão e mesmo da população. Por ora, entende-se que toda forma de conhecimento criado por meio de evidências empíricas e científicas reforça o papel da ciência para a gestão do turismo de sol e praia em um contexto pós-pandemia (Zielinski \& Botero, 2020; Hall et al., 2020).

\section{OS IMPACTOS DA PANDEMIA DA COVID-19 NAS PRAIAS MARÍTIMAS URBANAS NO BRASIL: CONJECTURAS E EVIDÊNCIAS}

As praias marítimas urbanas compreendem um importante atrativo para o desenvolvimento do turismo no Brasil, haja vista a predominância do clima subtropical, biomas expressivos como a Mata Atlântica que circunda as bordas litorâneas, abrigando e protegendo as praias e sua vegetação, além da paisagem costeira com as mais variadas características biogeomorfológicas, o que confere ao país um rico e atrativo ecossistema. São $8.500 \mathrm{~km}$ de linha de costa, de norte a sul (Martins-Silva \& Soriano-Sierra, 2013).

0 litoral do estado de Santa Catarina, que compreende $560 \mathrm{~km}$ de praias é reconhecido internacionalmente como um destino de verão, segundo Cristiano et al. (2018) e corroborado pelo Ministério do Turismo (2018). As características das praias, associadas à paisagem ambiental são as principais razões pelas quais os turistas escolhem o estado como destino de lazer (Cristiano et al., 2018; Ministério do Turismo, 2018). De 2014 a 2018, Florianópolis, Bombinhas, Balneário Camboriú e Itapema foram os destinos mais visitados dentro do estado (Ministério do Turismo, 2018). Em sua tese de doutorado, Garbuio (2019) aponta que o número de pessoas que frequentam as cidades costeiras turísticas catarinenses tem contribuído exponencialmente para a expansão da cadeia produtiva do turismo, em paralelo ao crescimento da construção civil e intensa especulação imobiliária. Balneário Camboriú, recebendo nas últimas temporadas de verão mais de 2 milhões de turistas, provenientes de todas as partes do país, como também da Argentina, Paraguai, Chile e Uruguai (Cristiano et al., 2018; Garbuio, 2019).

As praias e todo sistema costeiro abrigam intensa biodiversidade, além de cumprirem funções turístico-recreativas, econômicas, sociais, de proteção ao território adjacente e às atividades humanas. Constituem um dos espaços públicos mais democráticos e aprazíveis, apreciados por sociedades de toda parte do mundo. A Constituição Federativa do Brasil assim as respalda: "as praias são bens públicos de uso comum do povo, sendo assegurado, sempre, livre e franco acesso a elas e ao mar, em qualquer direção e sentido [...]", ressalvadas as áreas de segurança nacional (Brasil, 1988). Sua regulação está amparada pelas Leis n 7.661/1988 e 13.240/2015, derivadas, por sua vez, do Plano Nacional de Gerenciamento Costeiro (PNGC) de 1988.

O Decreto $n^{\circ}$ 5.300/2004, que regulamenta a Lei de Gerenciamento Costeiro, define critérios para a gestão da orla marítima, incluindo a descentralização da orla por parte da União para os municípios, cujo objetivo é disciplinar o uso e ocupação do território e promover uma gestão compartilhada, mais democrática 
e colaborativa entre os entes federativos. Desta forma, cada estado tem sua autonomia, com base no seu plano de intervenção e normas orientadoras, para decidir sobre o melhor planejamento urbano socioambiental, formas de uso e ocupação (Martins-Silva \& Soriano-Sierra, 2013).

Dado o contexto apresentado e, considerando o cenário global e nacional da pandemia da Covid-19, estados e municípios têm intensificado as medidas restritivas de distanciamento social, determinando, inclusive, a proibição de pessoas ao acesso às praias e calçadões das avenidas situadas nas faixas beira-mar, bem como praças e parques públicos ao ar livre, justificando propagação da pandemia por meio da aglomeração de pessoas nesses ambientes.

As praias urbanas sempre foram consideradas atrativos turísticos reais e potenciais (Martins-Silva \& Soriano-Sierra, 2013; Silva, 2013), por isso, elas podem apontar, neste momento, a uma inclinação latente para o seu uso em relação à intensidade de frequentadores. Segundo Souza Filho, Lins-de-Barros e Nunes (2020), devido ao seu potencial de aglomeração social, as praias de diversas cidades do mundo foram fechadas e seu uso proibido em função do elevado risco de contaminação pelo novo Coronavírus (Sars-Cov-2). Sem dúvida, esta é uma importante medida para o isolamento social, ação tão importante para diminuição da difusão da doença, mas que, com o passar dos meses e início do verão no hemisfério sul, as pessoas não têm respeitado tais regramentos e relaxando o seu comportamento.

Segundo Aquino et al. (2020), ao apontar que o distanciamento social envolve medidas que têm como objetivo reduzir as interações em uma comunidade, que pode incluir pessoas infectadas, ainda não identificadas e, portanto, não isoladas, foi num primeiro momento uma medida necessária, pois, em Santa Catarina, identificou-se um aumento de $484 \%$ do número de casos confirmados no período de 22 de março de 2020 (confirmação do primeiro caso de Covid-19) a 01 de abril de 2020, segundo Reginato et al. (2020). Isso implicou em medidas restritivas por parte do governo do estado, inclusive no acesso às praias.

Os estados costeiros que aderiram a esta conduta têm tido uma certa resistência por parte da sociedade local, como ressalta Meira (2020), ao justificar a medida no estado de Pernambuco: "A interdição de praias e praças públicas objetivando interromper ou ao menos reduzir a velocidade de transmissão do vírus se insere como absolutamente legítima a autorizar as medidas restritivas, em prol da preservação de vidas humanas e da saúde pública, mostrando-se razoáveis e proporcionais na atual conjuntura". A justificativa também é amparada pelo Decreto n 5.300/2004 e Lei $\mathrm{n}^{\circ} 13.240 / 2015$, quando sinalizam a proeminência dos próprios municípios para gerenciar estes bens, conquanto submetidos às orientações normativas da Secretaria do Patrimônio da União e à legislação federal, uma vez que tenham aderido à Gestão de Praias Marítimas (TAGP). Mesmo assim, os governos sentem-se pressionados para reabrir praias aos primeiros sinais de queda dos casos de Covid-19 e talvez até mais cedo, embora sob rígidas medidas de monitoramento e controle (Prideaux, Thompson, \& Pabel, 2020; Zielinski \& Botero, 2020).

Outro ponto a destacar nesse cenário epidêmico é a recuperação gradual da qualidade do meio ambiente das praias urbanas, especialmente aquelas cuja circulação de pessoas e usuários habitués promoviam algum tipo de erosão antrópica, ainda que pela simples absorção do impacto dos pés na superfície da areia da praia; ou seja, houve uma visual recuperação da granulometria da areia praial e o avistamento de espécies costeiras inerentes à fauna e flora, até então quase 
imperceptíveis. Isso indica o potencial de interferência negativa do ser humano no ecossistema praia. A ausência de pessoas na praia propicia a retomada da qualidade ambiental de outrora, enquanto a orla parece se assemelhar cada vez mais "àquela de tempos primitivos", relata Krelling (2020).

A ausência de banhistas, estes uma das principais fontes de lixo nas praias (Maziane, Nachite, \& Anfuso, 2018), tem sinalizado efeito positivo. Uma avaliação realizada nas praias brasileiras mostrou concentrações mais baixas do que o normal de plásticos e outros resíduos, normalmente encontrados na faixa de areia onde a maioria dos banhistas costuma se instalar (Fernandino \& Elliff, 2020). Em suma, a natureza tem um alto poder de resiliência, revelando nesses espaços e eventos que o problema está na pressão exercida pelas atividades humanas, obrigando os ambientes naturais a permanecerem em um nível de baixa conservação da biodiversidade. "Os ecossistemas não se comportam como vasos de porcelana frágeis que, ao menor contato alto, quebram e o erro não pode ser reparado" (Taverna \& Mantecón, 2020, p. 71). Diante disso, um cenário otimista decorrente da pandemia é o consumo sustentável do "turismo de sol e praia", mas ainda sem evidências claras (Zielinski \& Botero, 2020; Fernandino \& Elliff, 2020).

Por outro lado, ao refletir sobre o impacto social do fluxo de visitantes sobre os espaços públicos como as praias, sentimentos como insegurança, temor e apatia podem induzir as pessoas a adotar comportamentos evasivos durante e após a pandemia, no tocante ao consumo do produto turístico, contribuindo para o déficit do fluxo turístico decorrente dos impactos sanitários e psicológicos, transmitidos em escala mundial, do possível contágio, como já previsto e confirmado pela OMT (2020) e OMS (2020) (Malloy-Diniz et al., 2020; Zielinski \& Botero, 2020; Blake \& Sinclair, 2020, Gössling et al., 202). Este comportamento é esperado e caracteriza a elasticidade da demanda, pois segundo Blank e Sinclair (2020), a demanda turística é particularmente sensível à segurança e à saúde.

\section{PROCEDIMENTOS METODOLÓgICOS}

A pesquisa apresenta caráter exploratório e quantitativo, cujo objetivo é identificar a influência da Covid-19 no comportamento dos residentes de Balneário Camboriú - Santa Catarina, no uso dos espaços públicos naturais, com destaque para a orla e praias urbanas.

O método adotado para sua realização fundamentou-se no estudo de caso, referendado por Yin (2005) e Gil $(2010 ; 2012)$. Segundo os autores, por meio desse método, é possível afirmar a existência de uma "construção válida pela utilização de múltiplas fontes de evidências", incluindo a observação espontânea e sistemática do objeto ou unidade de análise, como explicam Pinsonneault e Kraemer (1993) sendo, neste caso, os espaços públicos (praias e orla) da cidade de Balneário Camboriú (SC).

A pesquisa por questionários (também conhecida como survey) foi conduzida visando identificar a percepção, comportamentos e expectativas de um grupo amostral de indivíduos, os quais representam os residentes permanentes do município outrora citado. Os atores que compuseram a amostra, não-probabilística, por conveniência e acessibilidade (Freitas \& Oliveira, 2000), seguiram os seguintes critérios de elegibilidade: a) ser residente permanente, b) residir em bairro central, incluindo 
a avenida beira mar, c) manter relação direta ou indireta com a atividade turística prestador de serviço, d) ser membro ativo da sociedade civil organizada. Ressalta-se que diante das medidas restritivas para o enfrentamento da Covid-19, a escolha apenas por moradores da cidade de Balneário Camboriú se deu por estes terem mais facilidades em usar os espaços públicos do que um visitante não residente.

O cálculo amostral foi estabelecido a partir da população oficial do IBGE (2020) para o município de Balneário Camboriú, estimada em 142.295 habitantes. Para obter o intervalo de confiança, assumiu-se que a amostra da população é verdadeiramente aleatória e representativa da população. Ao considerar este aspecto, estabeleceu-se um erro amostral de 5\%, com um nível de confiança de 99\%, sendo necessário 118 participantes para configurar uma amostra válida para a pesquisa (Freitas e Oliveira, 2000). No entanto, alcançaram-se 129 respondentes.

0 questionário fora construído pelo Google Forms e disponibilizado por meio de dois instrumentos, segundo a acessibilidade em banco de dados já existentes (e-mail e WhatsApp). Utilizou-se a estratégia do networking (redes de colaboração) a fim de atingir as pessoas elegíveis. Em síntese, a pesquisa foi disponibilizada online no período compreendido de 18 de maio a 18 de junho de 2020.

A relevância desta investigação é corroborada por Botero et al. (2020, p.27), quando explicam: "[...] vê-se uma excelente oportunidade para realizar questionários virtuais sobre a percepção que os visitantes têm das praias de um município ou inclusão de uma praia em particular".

\section{Destino estudo de caso - Balneário Camboriú - Santa Catarina}

Balneário Camboriú está localizado no litoral centro norte do estado de Santa Catarina, compreendendo uma área de $46,2 \mathrm{~km}^{2}$, distante a $80 \mathrm{~km}$ da capital do estado - Florianópolis e apresenta $22 \mathrm{~km}$ de extensão de costa. A Figura 1 situa o município de Balneário Camboriú no estado de Santa Catarina e, no Brasil.

Figura 1 - Localização geográfica Balneário Camboriú (SC).

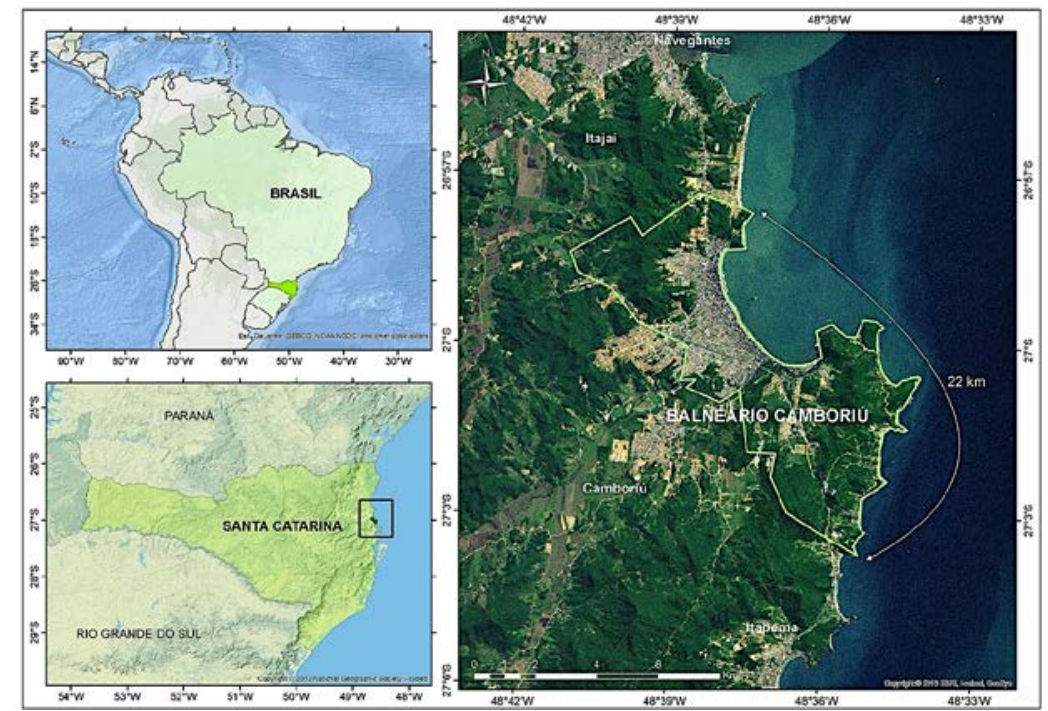

Fonte - Garbuio, 2019. 
A economia predominante em Balneário Camboriú está baseada no comércio, no turismo e na construção civil. A cidade é considerada um dos destinos turísticos nacionais mais consagrados, e um dos 65 municípios indutores de turismo do país, homologado pelo Ministério do Turismo (2018). É citado ainda como o $9^{\circ}$ destino brasileiro mais procurado por turistas para visitação, segundo a Fundação Instituto de Pesquisas Econômicas (FIPE) (Garbuio, 2019).

Balneário Camboriú é ainda reconhecida por sua criatividade e exuberância, pois nos últimos cinco anos têm criado e construído novas estruturas de entretenimento e lazer, com investimentos externos e inovação de toda ordem, apostando em um turismo elitizado. Todavia, o apelo de gestores e investidores aos espaços naturais tem contribuído para incorporar à cidade um cenário latente de artificializacão, com perigo iminente à qualidade e conforto ambiental como explica Garbuio (2019).

No tocante ao comportamento do município frente à pandemia do Coronavírus, uma das ações implementadas pela gestão pública em parceria com as entidades governamentais do município foi uma campanha de conscientização sobre o combate ao Coronavírus na região central, no dia 18 de julho, período em que as restrições de flexibilização passaram a ficar mais rígidas devido ao avanço da Covid-19 e cumprimento do decreto 9.999/2020 (Balneário Camboriú, 2020).

\section{Dimensões e critérios de observação dos espaços públicos no contexto da pandemia da Covid-19}

As dimensões elencadas para construir o questionário, visando atingir o objetivo da pesquisa, estiveram atreladas a três elementos subjetivos: comportamento (conjunto de reações diante da pandemia); percepção (impressões sensoriais diante da pandemia); e expectativa (crença centrada no futuro pós-pandemia). Todos eles foram contemplados tendo em vista sua correlação com o uso dos espaços públicos ao ar livre, com predominância das praias e orla marítima. 0 Quadro 1 demonstra os critérios estabelecidos para ponderação por parte dos informantes.

Quadro 1 - Matriz de avaliação de uso dos espaços públicos

\begin{tabular}{|c|c|}
\hline Dimensões & Critérios de observação \\
\hline $\begin{array}{l}\text { 1.Comportamento } \\
\text { (pessoal) }\end{array}$ & $\begin{array}{l}\text { - Fruição dos espaços públicos citadinos antes da pandemia } \\
\text { - Elementos de referência elencados aos espaços públicos } \\
\text { - Frequência de uso e permanência nos espaços públicos } \\
\text { - Distanciamento social nos espaços públicos }\end{array}$ \\
\hline $\begin{array}{l}\text { 2.Percepção } \\
\text { (de si, do próximo e do } \\
\text { ambiente externo) }\end{array}$ & $\begin{array}{l}\text { - Possibilidade de contágio pela Covid-19 nas praias e orlas } \\
\text { - Sentimentos e emoções pessoais em relação a pandemia } \\
\text { - Comportamentos das pessoas próximas ao usufruir dos } \\
\text { espaços públicos } \\
\text { - Melhoria na qualidade ambiental da praia e entorno } \\
\text { - Movimentação de pessoas nos espaços públicos }\end{array}$ \\
\hline $\begin{array}{l}\text { 3.Expectativa } \\
\text { (segurança e turismo) }\end{array}$ & $\begin{array}{l}\text { - Estimativa temporal de segurança nos espaços públicos no } \\
\text { tocante ao contágio do Coronavírus } \\
\text { - Recuperação do turismo no destino }\end{array}$ \\
\hline
\end{tabular}

Fonte - Elaborado pelos autores. 
Sentimentos foram mapeados como: medo, apatia, tranquilidade, insegurança e ansiedade, no tocante a si próprio. Alienação, medo, desrespeito, consciência, inconsequência e destemor foram sentimentos atrelados à percepção em relação ao outro e ao ambiente externo, incluindo, sobretudo, a expectativa em relação à recuperação do município no tocante ao turismo.

Malloy-Diniz et al. (2020) publicaram um estudo relacionado à mudança de comportamento e atitude, seja em relação à adoção de medidas protetivas, seja na manutenção de uma boa saúde mental ou no planejamento de uma vida pós-pandemia, que, segundo os autores, passam a figurar como cruciais no momento atual. Em Malloy-Diniz et al. (2020), com a orientação de isolamento social, faz-se necessário compreender como os diferentes níveis de comportamentos impactam e são impactados pelo distanciamento social e pela diminuição de oportunidades de prática motora. Para este estudo, o impacto se dá na relação do indivíduo com o espaço público.

\section{RESULTADOS E DISCUSSÃo}

Os resultados da pesquisa são apresentados a seguir, divididos em duas seções interdependentes: perfil dos entrevistados e pesquisa survey realizada com os residentes de Balneário Camboriú (SC) com as três dimensões propostas.

\section{Perfil dos Entrevistados}

O grupo amostral é inteiramente residente no município de Balneário Camboriú, Santa Catarina, e seu perfil é apresentado nesta seção. A maioria dos respondentes satisfez o gênero feminino $(72,1 \%)$, adultos e em idade economicamente ativa $(64,14$, soma das duas classes 30-40 e 41-50) (Gráfico 1, Tabela 1).

\section{Gráfico 1 - Gênero}

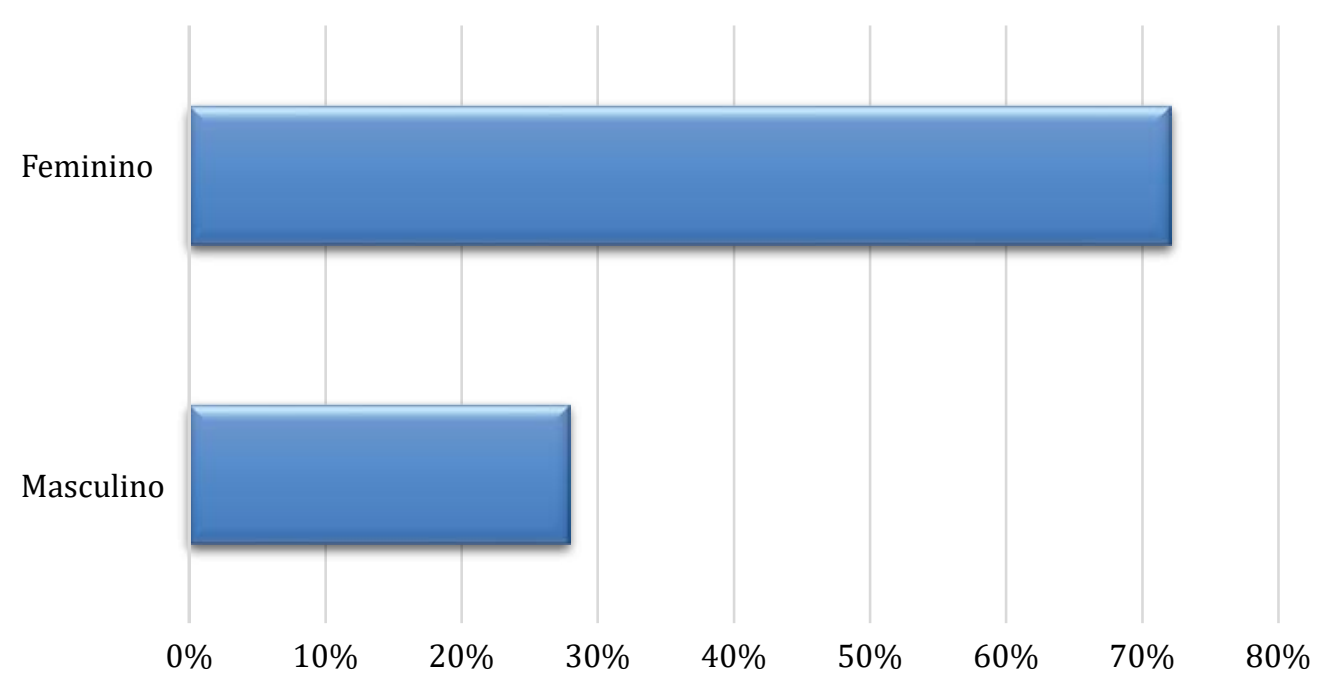

Fonte - Elaborado pelos autores. 
Tabela 1 - Faixa etária

\begin{tabular}{|c|c|}
\hline Faixa etária & $\mathbf{\%}$ \\
\hline Abaixo de 30 & 7,32 \\
\hline $30-40$ & 28,04 \\
\hline $41-50$ & 36,10 \\
\hline $51-60$ & 23,05 \\
\hline Acima de 60 & 5,49 \\
\hline Total geral & $\mathbf{1 0 0 \%}$ \\
\hline Fonte - Elaborado pelos autores.
\end{tabular}

Já o nível de escolaridade é relativamente alto, com 88,54\% para superior completo e 4,81\% superior incompleto, como ilustra a Tabela 2 . A esse respeito, estudos de Rodrigues, Santos, Teixeira, Gonela e Zanetti (2012); Moura e Masquio (2014) e Congro (2005) avaliam que o nível de escolaridade é determinante para as práticas de saúde (cuidados médicos e alimentares) e tomadas de decisão, como também, em geral, situam-se em faixas de renda mais alta, no entanto esta variável não foi aferida na pesquisa. Por sua vez, Congro (2005, p.76), em sua pesquisa, aponta que as pessoas com alto grau de escolaridade "[...] tendem a viajar várias vezes por ano e, portanto, apresentam um nível de exigência maior em relação aos serviços que lhes são prestados", assim, exercendo grande influência na tomada de decisão. Portanto, pode-se inferir que os entrevistados também terão um alto grau de exigência na avaliação em tela.

Tabela 2 - Escolaridade

\begin{tabular}{|l|c|}
\hline Escolaridade & $\mathbf{\%}$ \\
\hline Ensino fundamental completo & 1,78 \\
\hline Ensino fundamental incompleto & 1,25 \\
\hline Ensino médio completo & 3,15 \\
\hline Ensino médio incompleto & 0,48 \\
\hline Superior completo & 88,54 \\
\hline Superior incompleto & 4,81 \\
\hline Total geral & $\mathbf{1 0 0 \%}$ \\
\hline \multicolumn{1}{|c|}{ Fonte - Elaborado pelos autores. } \\
\hline
\end{tabular}

A baixa escolaridade, por sua vez, apresentada por Moura e Masquio (2014), sugere que a população menos escolarizada pode estar mais suscetível a interpretações errôneas sobre conceitos de alimentação e nutrição e alertam para a necessidade de programas de educação alimentar voltadas para esse público. De acordo com Rodrigues et al. (2012), embora o conhecimento seja um pré-requisito para o autocuidado, este pode não ser o único e principal fator envolvido em uma análise de comportamento. Tendo em vista que ao se tratar sobre a Covid-19, existe também a divulgação de fake news que dificultam o reconhecimento das medidas protetivas contra a doença. De forma geral, Wang et al. (2020) explicam que a relação 
entre o nível de escolaridade e o comportamento de prevenção e cuidados com a saúde podem refletir na influência do nível socioeconômico, no caso da Covid-19.

\section{Dimensão 1: Comportamento}

O perfil comportamental apresentado no Quadro 1, correlaciona suas decisões preliminares no período de distanciamento social para uso dos espaços públicos, como praias e orla marítima da cidade.

Observa-se que o uso dos espaços públicos é uma prática cotidiana dos munícipes (Gráfico 2), sendo a praia o local de permanência mais apreciado por eles (Gráfico 3), com 62,8\% de adesão. No entanto, com a pandemia, um dos efeitos sociais que se constata está na forma paradoxal de interação e percepção da sociedade com o espaço público.

\section{Gráfico 2 - Uso dos espaços públicos citadinos}

\section{Anteriormente ao surgimento da pandemia do covid -19 , você costumava frequentar os espaços públicos da cidade de Balneário Camboriú?}

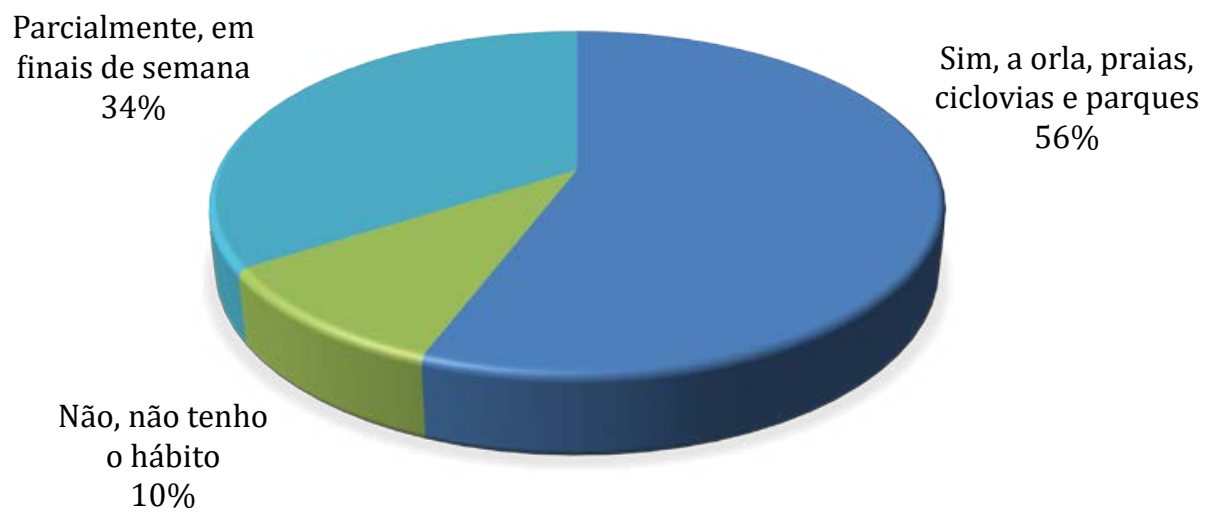

Fonte - Elaborado pelos autores.

Gráfico 3 - Elementos de referência apreciados nos espaços públicos citadinos

$$
\begin{gathered}
\text { Qual(is) é (são) o(s) elemento(s) de referência para sua permanência nos } \\
\text { espaços públicos da cidade }
\end{gathered}
$$

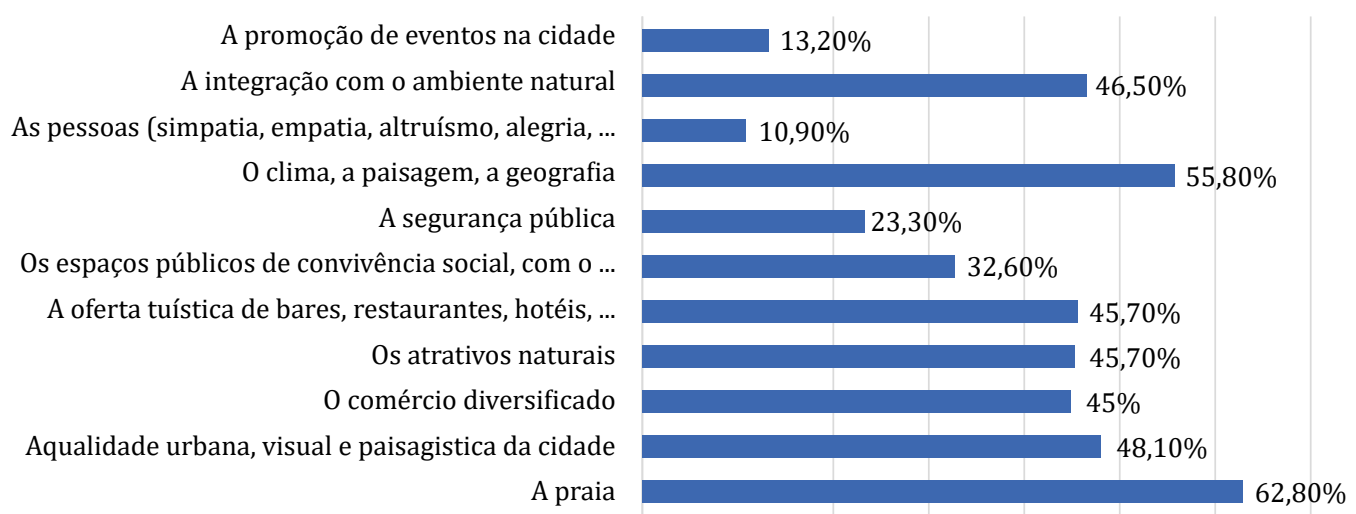

Fonte - Elaborado pelos autores. 
Tendo em vista que as regras que condicionam os deslocamentos e saídas diárias são restritivas, e visando diminuir as possibilidades de contágio, observa-se que os entrevistados declaram que elas foram acatadas por uma grande maioria (Gráfico 4), contudo, desrespeitadas de forma parcial e total por 29,5\% dos mesmos. Como as condições sanitárias impostas pela pandemia têm sido rígidas e restringiram as atividades preferidas dos residentes (praia), isto pode ter impactado ou acelerado na percepção do comportamento quando se avalia as atividades realizadas pelo "outro".

Gráfico 4 - Comportamento do entrevistado nos espaços públicos no período da pandemia

Neste período de pandemia, como tem sido seu comportamento com relação ao uso dos espaços públicos

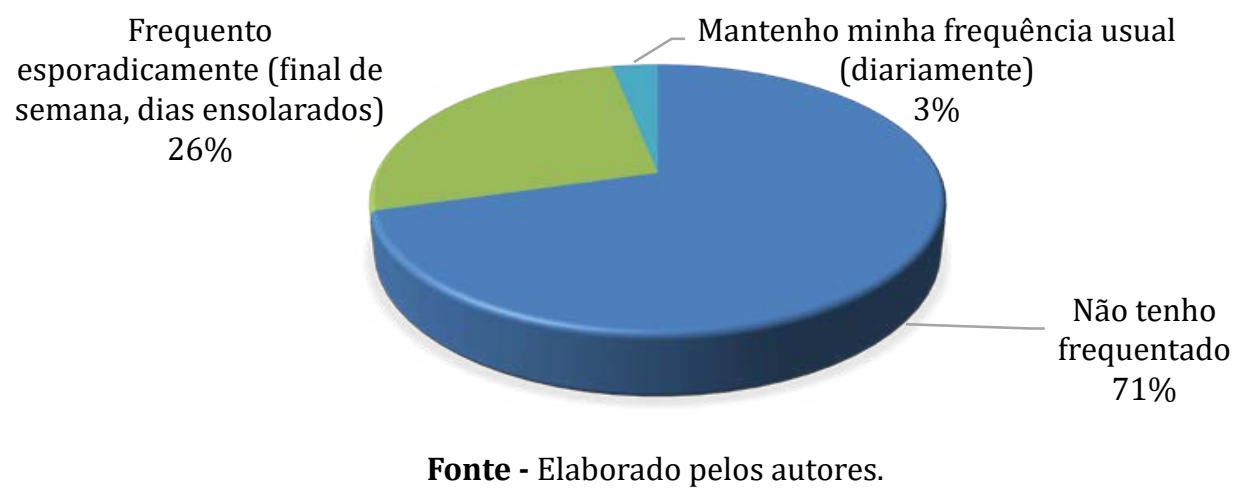

Neste sentido, ao analisar a pergunta "como você enquadraria o comportamento dos outros", o isolamento ou distanciamento no uso do espaço cai para 10,1\% (Gráfico 5). É perceptível que essas mudanças sinalizadas pela dimensão do comportamento são contraditórias.

Ainda assim, essa contradição é defendida por Pereira (2016). 0 seu estudo indica que as pessoas que consomem a praia urbana se caracterizam pela pluralidade de desejos. A autora afirma que: "0 desejo é claramente desnudado no ambiente praiano, revela-se na natureza praia, o que permite pensar para além dos limites do ambiente praiano, sobre uma sociedade que promove a possibilidade (negativa) de produção do desejo pela liberdade, na medida em que as pessoas buscam a sua realização na faixa-de-areia" (Pereira, 2016, p.196). Ao comparar as respostas da dimensão comportamento, estas corroboram com a tese de que o "clima" praiano, segundo Pereira (2016), configura o desejo e a diversidade de escolhas na convivência pública e a pluralidade de práticas no litoral.

Outra consideração acerca desta matéria é descrita por Malloy et al. (2020). Segundo os autores, em face do cenário atual, [...] hábitos que eram praticados de forma rotineira hoje se mostram bastante disfuncionais. Então, "a partir de uma perspectiva baseada em AppliedBehaviorAnalysis (ABA), devemos considerar que as regras puras e simples não garantem a mudança de comportamento" (Malloy et al., 2020, p. 8).

É evidente que as condições sociais e a propensão individual para continuar com o isolamento se alteram ao longo do tempo, como afirma Spiess (2020), tendo em vista que a coleta do questionário foi realizada no período de 18 de maio 
a 18 de junho de 2020. Neste interstício, o governo do estado de Santa Catarina, por meio do decreto 630 de $1^{\circ}$ de junho de 2020, flexibilizou o distanciamento social. Este tipo de comportamento pode ter efeitos da pressão de segmentos da sociedade pelo fim do isolamento. A aversão individual ao risco não pode ser prejudicada pelas tendências institucionais.

Gráfico 5 - Distanciamento social nos espaços públicos no período da pandemia

Como você enquadraria o distanciamento social das pessoas nos espaços públicos?

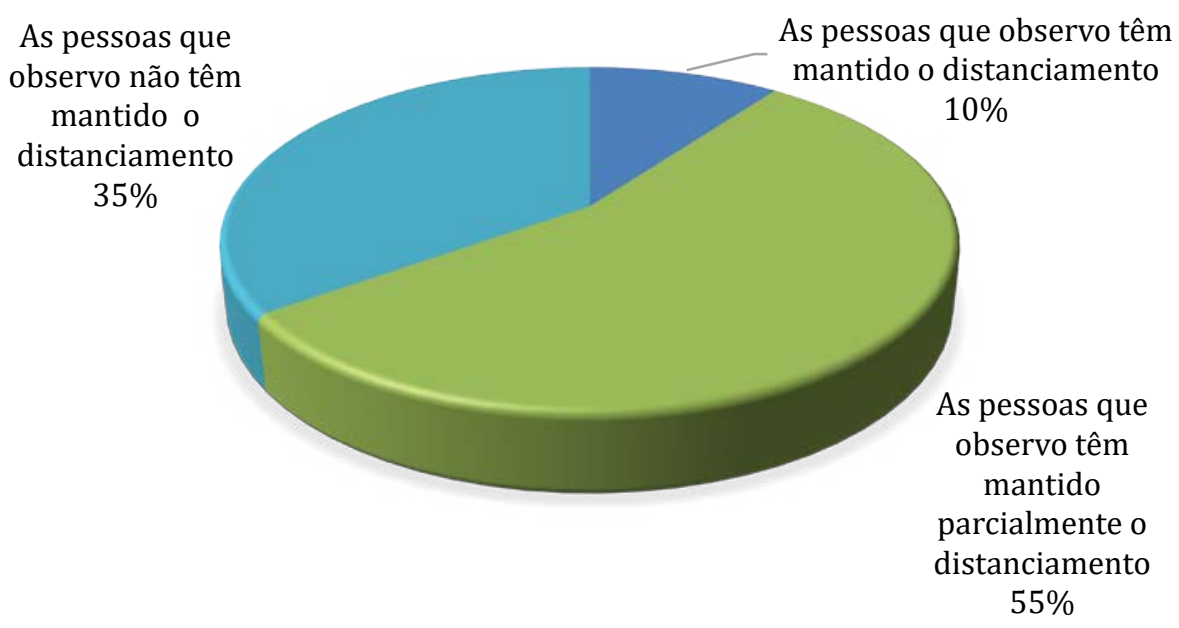

Fonte - Elaborado pelos autores.

\section{Dimensão 2: Percepção}

A forma como as pessoas reagem em uma situação de crise, como as pandemias, pode variar grandemente, determinando não apenas os cuidados dirigidos a elas, mas também o envolvimento das mesmas com relação ao próximo e ao seu ambiente externo (Malloy et al., 2020, p. 6). A percepção é determinada pelo conjunto de emoções, crenças, valores, sentimentos e experiências vivenciadas (sejam reais ou emocionais) e poderá materializar-se na forma de atitudes e comportamentos. No atual cenário, a percepção individual tende a modular as atitudes e influenciar a decisão da população em frequentar ou não os espaços públicos no período da pandemia da Covid-19.

Segundo Mattedi, Ribeiro, Spiess e Ludwig (2020, p. 286), "toda projeção de cenários pós-Covid-19 supõe mudança social. A mudança social constitui uma transformação observável ao longo do tempo, do padrão de funcionamento da organização do contexto social". Desta forma, a dimensão percepção traz este indicador importante a respeito de como o morador de Balneário Camboriú faz juízo ao uso do espaço público em tempos de pandemia.

Ao observar o perfil do público participante da pesquisa $(88,6 \%$ com formação universitária), surpreende que em $31 \%$ ainda existam dúvidas a respeito das possibilidades de contágio da Covid-19 (Gráfico 6). Este dado assinala que, apesar de haver uma alta concentração de respondentes com alto grau de instrução educacional que compreende os usuários da orla da cidade, estes não estão fazendo uso das regras sanitárias e do distanciamento social. Esse comportamento sinaliza, de certa forma, que tais decisões dificultam o enfrentamento da pandemia. Ao não 
levar em consideração as informações das orientações, amplamente divulgadas pelos meios de comunicação, pode-se entender que estas respostas se aproximam ao comportamento dos denominados negacionistas, conforme aponta Caponi (2020).

Gráfico 6 - Crença na possibilidade de contágio pelo Covid-19 na praia e orla

Você acredita na possibilidade de se contagiar pelo Covid-19 ao frequentar a praia e os espaços inerentes à orla?

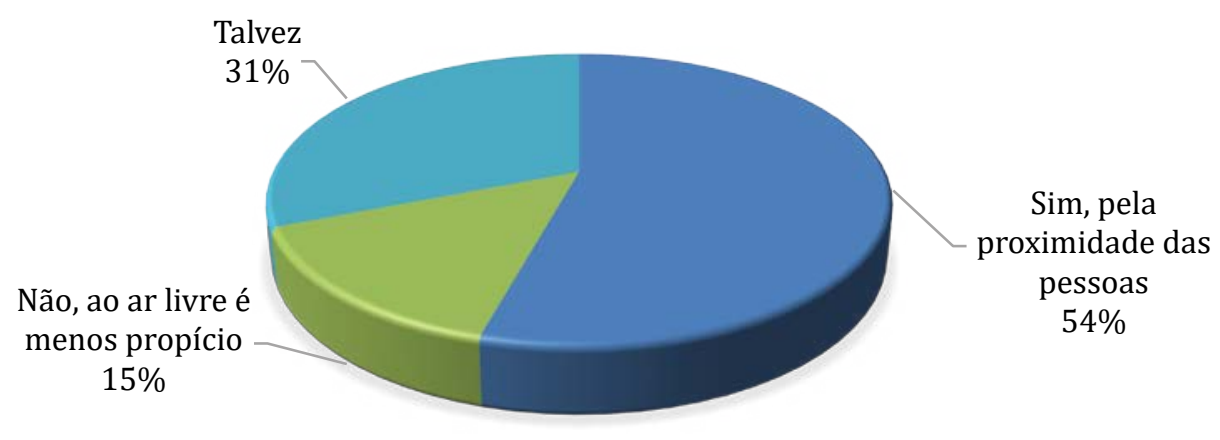

Fonte - Elaborado pelos autores.

A disseminação de informação falsa contribui para o agravamento da ansiedade das pessoas durante a pandemia na fruição do espaço público, demonstrando que 35,7\% se sente inseguro(a) ao frequentá-lo(a) (Gráfico 7), como também sinalizam Zielinski e Botero (2020). 0 resultado aponta que a pandemia afeta ainda mais o cotidiano e a saúde psicoemocional das pessoas, também corroborada por Malloy-Diniz et al. (2020), pois provocou ansiedade e apatia, além do medo. Apenas 20,2\% dos entrevistados declararam que se sentiam seguros ao estar no "ambiente praia/orla", sem qualquer receio de se contaminar. Por sua vez, ao avaliar o outro, a percepção se altera. Para os entrevistados, existem mais pessoas conscientes sobre a necessidade em se manter distantes dos/nos espaços públicos durante a pandemia, quando comparado a eles mesmos (Gráfico 8).

Gráfico 7 - Sentimentos inerentes a pandemia da Covid-19

Como você se percebe (sensação) nesse momento da pandemia?

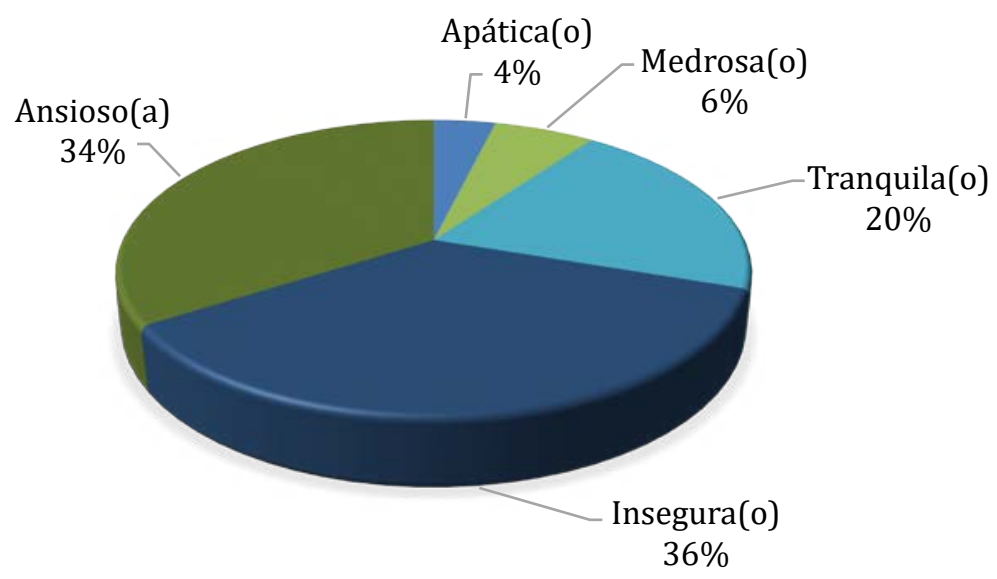

Fonte - Elaborado pelos autores. 
Gráfico 8 - Comportamento alheio, inerente a pandemia da Covid-19 (percepção)

Como você percebe as demais pessoas que residem em sua cidade? Amigos, vizinhos, parentes... ao observar sua rotina de fruição nos espaços públicos?

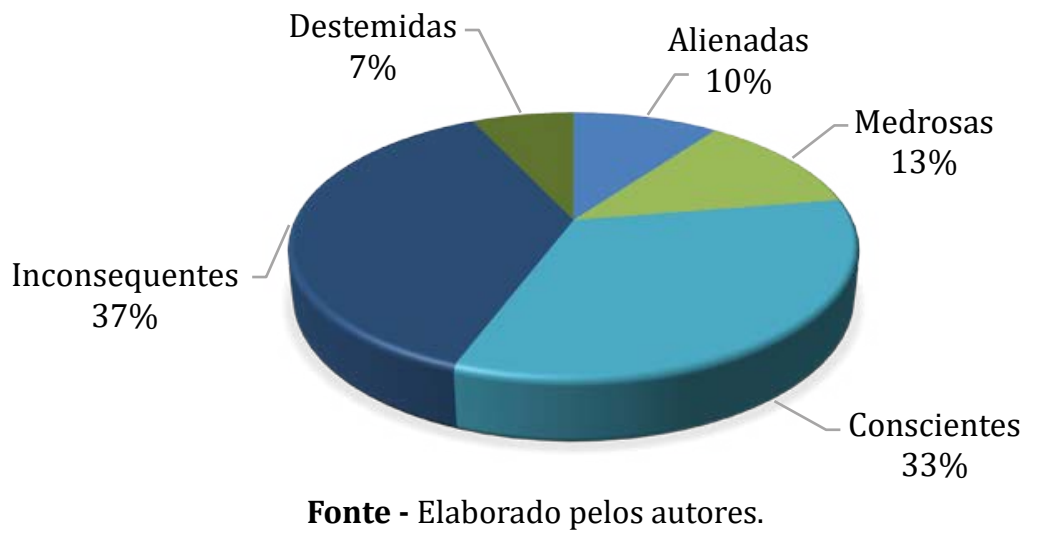

A diferença entre a autoavaliação e a avaliação sobre os outros reforça a importância de se considerar a diversidade de visões sobre a letalidade da pandemia na análise dos dados. 0 que o sujeito entende como postura individual não reflete exatamente com a do coletivo. Desta forma, é necessário compreender que são cenários distintos e que não podem ser avaliados a partir de uma percepção de forma unidimensional, pois o processo social em análise é uma combinação de práticas individuais e coletivas. Ao serem inquiridos sobre a percepção dos outros sobre a disseminação da Covid-19 na praia ou na orla, a pesquisa mostrou que existe um grupo majoritário que nega ou mesmo demonstra tranquilidade ao continuar a frequentar os espaços $(55,8 \%)$, contrariando toda a determinação do distanciamento social (Gráfico 9).
Gráfico 9 - Comportamento dos espaços públicos, inerente a pandemia do Covid-19 (percepção)

\section{Em sua percepção, no período de disseminação da pandemia do covid-19, as praias e demais espaços públicos de Balneário Camboriú, tem se revelado:}

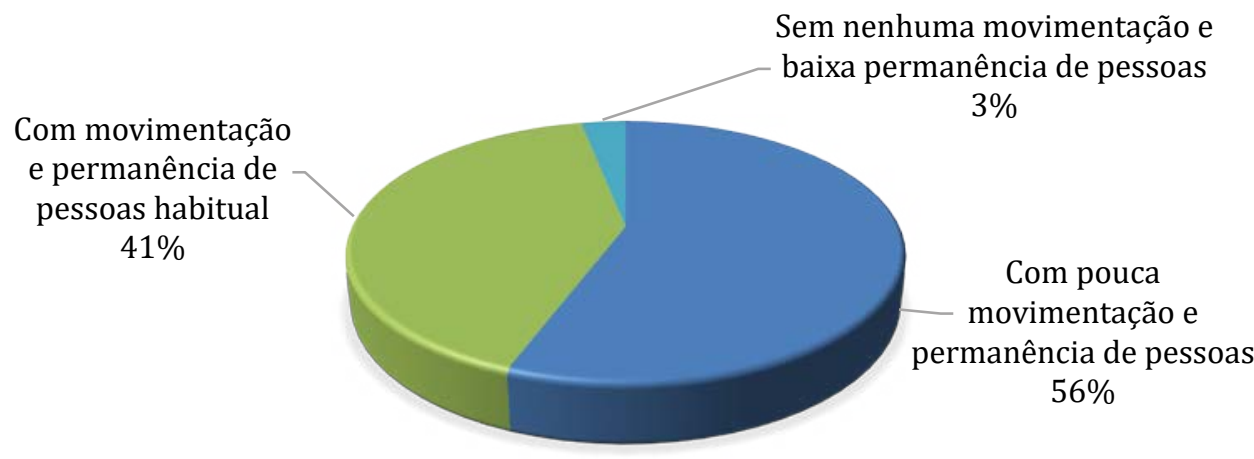

Fonte - Elaborado pelos autores. 
Por outro lado, apesar deste indicativo negativo, houve a percepção de que o espaço costeiro sofreu mudanças positivas. 0 impacto da restrição da mobilidade dos usuários trouxe efeitos positivos na qualidade ambiental (Gráfico 10) como a limpeza e qualidade da água, também confirmado por Zielinski e Botero (2020) e Fernandino e Elliff (2020).

Gráfico 10 - Melhoria da qualidade ambiental das praias urbanas citadinas (percepção)

Você identificou se houve alguma melhoria na qualidade ambiental da praia? Quais?

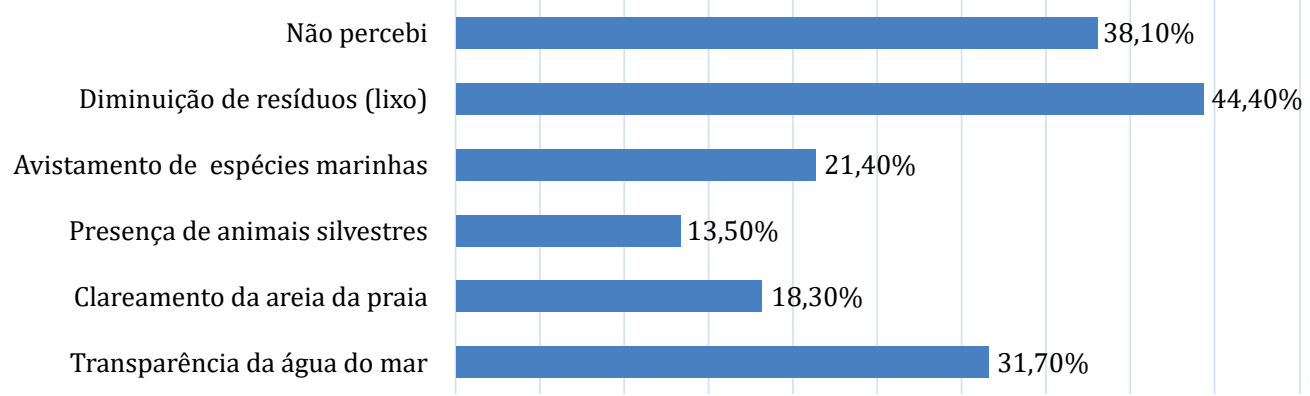

0,00\% 5,00\% 10,00\%15,00\%20,00\%25,00\%30,00\%35,00\%40,00\%45,00\%50,00\%

Fonte - Elaborados pelos autores.

Botero et al. (2020) trazem uma análise que, à primeira vista, pode parecer polêmica, mas que, indubitavelmente, é consensual por meio da percepção visual. "O que realmente estamos presenciando como reação da natureza a esta pandemia fatal é o retorno e o crescimento dos processos naturais e mecanismos de autorregulação dos quais dispõem os ecossistemas costeiros, graças a uma base dinâmico-funcional natural que ainda se mantêm, apesar de tantas mudanças e transformações antropogênicas que lhes têm sobreposto" (Botero et al., 2020, p.17). Souza Filho et al. (2020, p. 64) confirmam:

Não demorou, então, para que aparecessem nas redes sociais imagens de praias famosas e lotadas de pessoas, agora completamente vazias, revelando uma paisagem rara do ambiente praial apenas com areia, vegetação e dunas; do mar junto ao litoral sem embarcações, somente com suas ondas de espumas brancas e águas mais claras do que se costumava ver e, por vezes, com animais marinhos antes pouco avistados.

Eis aí um dos impactos positivos a que a pandemia da Covid-19 trouxe para o mundo - a recuperação ambiental e o restabelecimento da vegetação costeira, como restinga e campo de dunas.

\section{Dimensão 3: Expectativa}

A expectativa, neste estudo, visa aferir o grau de confiança a que os residentes esperam na recuperação da economia do turismo e na segurança individual quanto a sua mobilidade e interação social.

Ao questionar os residentes sobre uma previsão de retorno à vida cotidiana com a frequência habitual às praias e orla da cidade, $71 \%$ demonstraram insegurança. Garbuio (2019) expõe que o meio ambiente urbano é o local de encontro das pessoas, que deve acima de tudo, propiciar bem-estar, conforto ambiental, 
segurança, confiança e qualidade no caráter de envolvimento entre elas e, também, com o ambiente. Logo, esta premissa não satisfaz a realidade atual dos espaços públicos citadinos em tempos de pandemia.

Gráfico 11 - Expectativa temporal de segurança em relação à pandemia da Covid-19
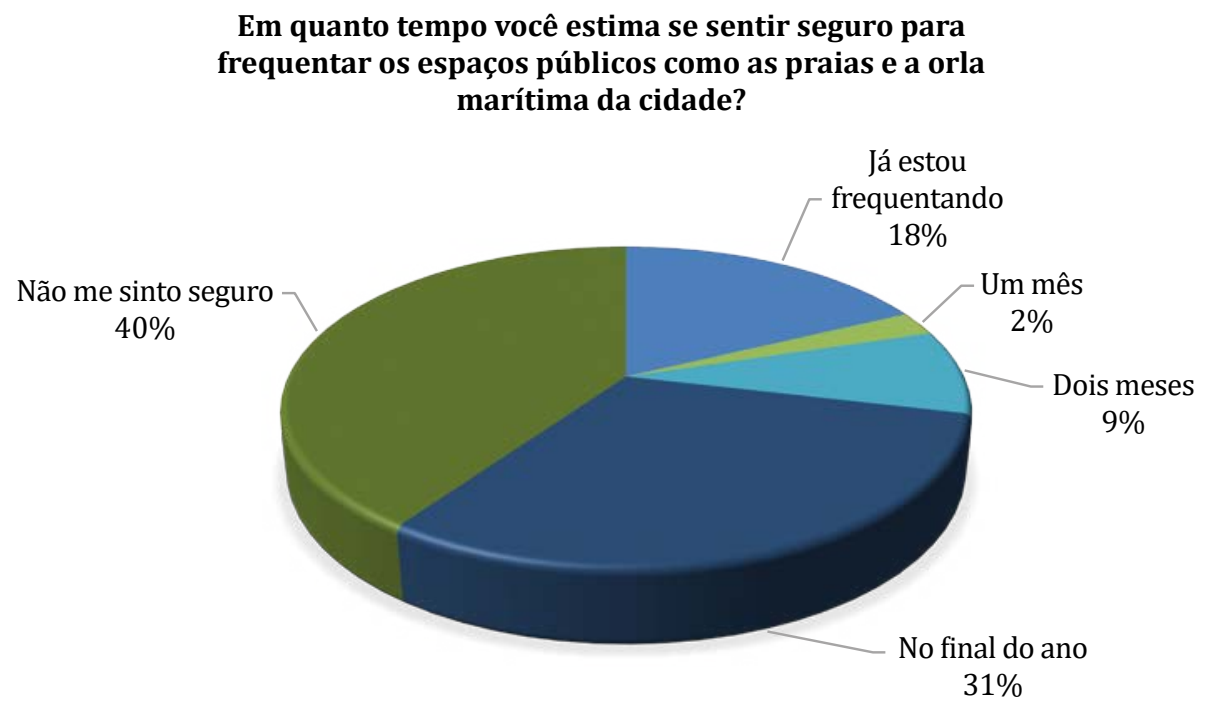

Fonte - Elaborado pelos autores.

Os dados sinalizam que, se os habitués tendem a se comportar com cautela, o fluxo turístico também tenderá a retornar de forma lenta, como demonstra o Gráfico 12, seguindo a mesma tendência. Isso revela, por sua vez, ainda mais insegurança por parte da população residente, que depende em grande proporção das atividades econômicas do turismo.

Gráfico 12 - Expectativa em relação à retomada do turismo pós-pandemia da Covid-19

Qual a sua expectativa em relação ao turismo em Balneário Camboriú:

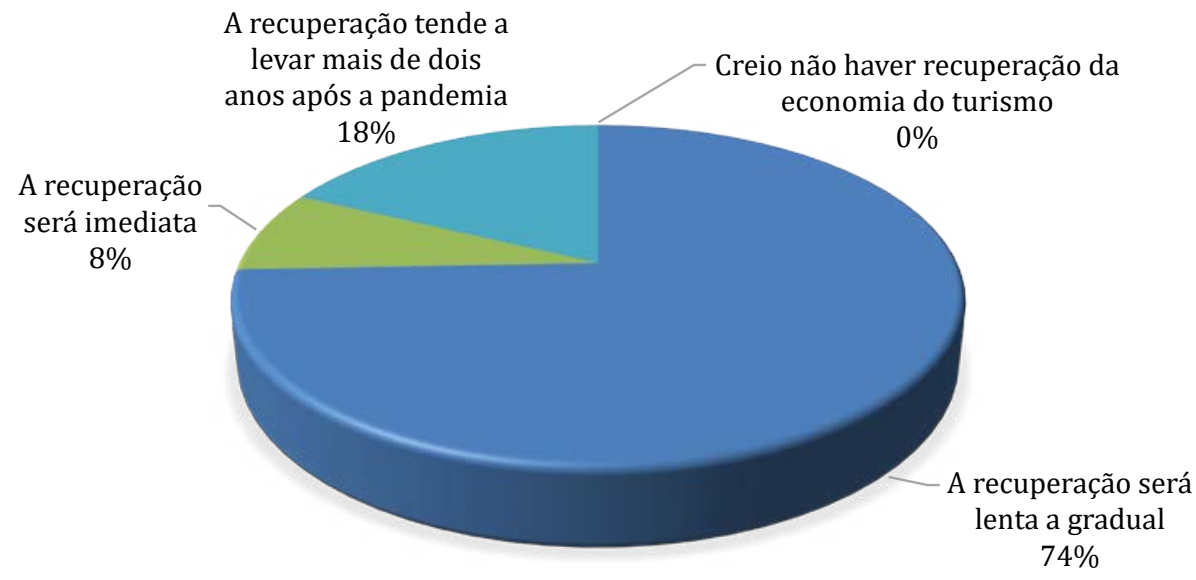

Fonte - Elaborado pelos autores. 
Em suma, apreende-se que sentimentos de apreensão se manifestam para diferentes variáveis decorrentes da pandemia, quais sejam: circulação e ocupação das praias e orla; recessão econômica do turismo local; e, inclusive, saúde mental.

\section{CONSIDERAÇÕES FINAIS}

O estudo aponta dados e informações que retratam uma realidade local, que se mostra ainda transitória, haja vista a pandemia da Covid-19 ser um fenômeno inédito no mundo. Por isso, a análise e suas considerações referem-se a um momento atual e ainda em curso. Ao mesmo tempo em que medidas de combate à Covid-19 são baseadas em evidências científicas, a ciência também mostra sua fragilidade nesse momento. As decisões têm sido tomadas mais pelo temor e baseadas nos piores cenários de modelagens preliminares, alimentadas com dados parciais e incompletos de uma história ainda sem desfecho. Somado a isso, a escassez de literatura disponível, e nenhuma de ótima qualidade em termos de nível de evidencia (Malloy-Diniz et al., 2020).

Cabe ressaltar que o assunto outrora discutido tem assumido relevantes repercussões no campo do turismo, mas é prematuro afirmar suposições e/ou soluções para uma crise inédita, sem precedentes na história. Mesmo assim, por meio de observações e evidências científicas, agrupadas em áreas de conhecimento multidisciplinares, apresentou-se neste estudo, reações de uma comunidade que em muito contribui para o desenvolvimento do turismo de uma destinação seus residentes permanentes. Ademais, mesmo não abordando nenhum turista no destino, os resultados ajudam a compreender os possíveis impactos da Covid-19 no setor de turismo.

Apesar da dificuldade de mensurar as mudanças sociais que a Covid-19 impôs aos hábitos dos munícipes no uso do espaço público da orla de Balneário Camboriú, verificou-se que o comportamento de alguns tem implicado em efeitos abrangentes. Essas implicações repercutem na negação ou mesmo no rompimento das regras de isolamento social, prejudicam a conscientização coletiva e o enfrentamento da pandemia. Por vezes, aparentam sinais de alienação, desinteresse e apatia aos acontecimentos.

Muito embora dos $88 \%$ dos entrevistados tenham respondido que se enquadram em nível superior de formação, nota-se descrença e rebeldia por parte destes. Isso pode ser reflexo do comportamento coletivo, resultante de um conjunto de elementos tais como: a perda de confiança nas ações governamentais, por prolongarem o isolamento social; a pouca efetividade das medidas sanitárias; o amplo consumo de informações duvidosas que tendem a alimentar a insegurança, o medo e dúvidas pela retomada da rotina anterior a pandemia.

Especialistas em infectologia recomendam que a prática de atividades esportivas ao ar livre auxilia na imunidade do indivíduo e, portanto, causa uma defesa maior ao vírus, mas, ao encontro disso, tem-se ao mesmo tempo, o embate da aglomeração de pessoas no espaço público, que pode disseminar o vírus. Para uma cidade costeira e turística, tem-se um dilema que pode se mostrar incontroverso. Logo, percebe-se que, até que o mundo obtenha uma vacina e informações legítimas com base na ciência, a vulnerabilidade de uma sociedade inteira é iminente. Por outro lado, essa é a oportunidade para que os prestadores locais de serviços 
turísticos pensem globalmente e estabeleçam sinergias com outros prestadores que os complementam, seja na sua localidade ou em qualquer outro lugar do planeta. É a oportunidade para que os gestores das praias troquem experiências com seus pares em todo o continente, criando redes de colaboração para um novo tempo, uma nova faceta da sustentabilidade nas praias.

As conclusões aqui apresentadas têm caráter anedótico e servem, acima de tudo, como um referencial para compreender as diferentes dinâmicas que estão presentes na costa brasileira, incluindo mais uma novidade - a pandemia da Covid-19. Seguramente há ainda outros municípios costeiros com diferentes conjunturas, que também nos trariam outras percepções sobre a melhor forma de compreender o comportamento dos residentes para com os efeitos dessa pandemia. Concorda-se com o que relatam Souza Filho et al. (2020) onde o contraste de imagens das praias lotadas com o vazio, permitindo contemplar uma outra paisagem (mais natural). Esta é a outra face da pandemia. É a resposta da natureza para o alívio da pressão humana sobre o pulmão de seu ecossistema. Infelizmente, a possibilidade de uma nova visão das praias e demais ecossistemas costeiros ocorre em função de uma catástrofe responsável pela perda de tantas vidas humanas.

\section{REFERÊNCIAS}

Aquino, E. M., Silveira, I. H., Pescarini, J. M., Aquino, R., \& Souza-Filho, J. A. D. (2020). Medidas de distanciamento social no controle da pandemia de COVID-19: potenciais impactos e desafios no Brasil. Ciência \& Saúde Coletiva, 25, 2423-2446. DOI: https://doi.org/10.1590/1413-81232020256.1.10502020

Balneário Camboriú (2020). Central de informações Coronavírus. Pacto por BC leva conscientização a região central. Recuperado de http://www.secuidabc.com.br/ noticias/pacto-por-bc-leva-conscientizacao-a-regiao-central. Acesso em: 18 jul. 2020.

Blake, A., \& Sinclair, M. T. (2003). Tourism Crisis Management. Annals of Tourism Research, 30(4), 813-832. DOI: https://doi.org/10.1016/S0160-7383(03)00056-2.

Botero, C.M., Mercadé, S., Cabrera, J.A., \& Bombana, B. (eds.) (2020). 0 turismo de sol e praia no contexto da Covid-19: cenários e recomendações. Publicação no marco da Rede Iberoamericana de Gestão e Certificação de Praias - PROPLAYAS. Santa Marta (Colômbia).

Brasil, S. F. (1988). Constituição da república federativa do Brasil. Brasília: Senado Federal, Centro Gráfico.

Caponi, S. (2020). Covid-19 no Brasil: Entre o negacionismo e a razão neoliberal. Estudos Avançados, 34(99), 209-224. DOI: https://doi.org/10.1590/s0103-4014.2020.3499.013.

Cristiano, S. da C.; Portz, L. C.; Anfuso, G.; Rockett, G. C.; \& Barboza, E. G. (2018). Coastal scenic evaluation at Santa Catarina (Brazil): Implications for coastal management. Ocean \& Coastal Management, 160,146-157. DOI: https://doi.org/10.1016/j.ocecoaman.2018.04.004.

Congro, C. R. (2005). Análise do perfil e da satisfação dos turistas da cidade de Corumbá (MS) visando à adequação dos empreendimentos turísticos da região (Dissertação de Mestrado). Programa de Pós-Graduação Stricto Sensu em Turismo e Hotelaria. Balneário Camboriú, 117p.

Cucinotta, D., \& Vanelli, M. (2020). WHO declares COVID-19 a pandemic. Acta bio-medica: Atenei Parmensis, 91(1), 157-160. DOI: 10.23750/abm.v91i1.9397. 
Fernandino, G.; \& Elliff, C.I. (2020). Um olhar sobre a composição e abundância de lixo nas praias durante e após a pandemia pela Covid-19. In El Turismo de sol y Playa en el Contexto de la COVID-19. Escenarios y Recomendaciones; Botero, C.M., Cabrera, J.A., Mercadé, S., Bombana, B., Eds.; Red Iberoamericana Proplayas: Santa Marta, Colombia; pp. 68-70.

Garbuio, M.E.M.S. (2019). Espaços públicos humanizados e sustentáveis: cocriação e consolidação de um framework para cidades costeiras turísticas, sob a perspectiva do European Smart Cities Model. (Tese de Doutorado). Programa de Pós-Graduação em Engenharia em Gestão do Conhecimento. Universidade Federal de Santa Catarina. Florianópolis. 875p.

Goodrich, J. N. (2002). September 11, 2001 Attack on America: Impact on Tourism Security. Journal of Travel \& Tourism Marketing, 11(4), 1-12. DOI: https://doi.org/10.1300/ J073v11n04_01

Gössling, S., Scott, D., \& Hall, C. M. (2020). Pandemics, tourism and global change: A rapid assessment of COVID-19. Journal of Sustainable Tourism, 29(1), 1-20. DOI: https://doi.org/10.1080/09669582.2020.1758708

Hall, C. M., Scott, D., \& Gössling, S. (2020). Pandemics, transformations and tourism: Be careful what you wish for. Tourism Geographies, 22(3), 577-598. DOI: https://doi.org/10.1080/ 14616688.2020.1759131

IBGE - Instituto Brasileiro de Geografia e Estatística. (2020). Balneário Camboriú: Panorama. Recuperado de https://cidades.ibge.gov.br/brasil/sc/balneario-camboriu/panorama. Acesso em: 15 jul. 2020.

Krelling, A. P. (2020). 0 papel das pequenas cidades balneárias na pandemia de COVID-19. In: Botero, C.M., Mercadé, S., Cabrera, J.A., Bombana, B. (editores). 0 Turismo de sol e praia no contexto da Covid-19. Cenários e recomendações. Publicação no marco da Rede Ibero-americana de Gestão e Certificação de Praias - PROPLAYAS. Santa Marta (Colômbia), 58-60.

Malloy-Diniz, L. F., Souza Costa, D. S., Loureiro, F., Moreira, L., Silveira, B. K. S., Sadi, H. M., ... Miranda, D. (2020). Saúde mental na pandemia de Covid-19: considerações práticas multidisciplinares sobre cognição, emoção e comportamento. Debates em psiquiatria, 46-68.

Martins-Silva, M. E., \& Soriano-Sierra, E. J. (2013). Gestión sustentable de la orla marítima en destinos turísticos: una perspectiva social sobre el proyecto ORLA. Estudios y perspectivas en turismo, 22(4).

Mattedi, M. A., Ribeiro, E. A. W., Spiess, M. R., \& Ludwig, L. (2020). Epidemia e contenção: cenários emergentes do pós-Covid-19. Estudos Avançados, 34(99), 283-302. Epub July 10, 2020. DOI: https://doi.org/10.1590/s0103-4014.2020.3499.017

Maziane, F., Nachite, D., \& Anfuso, G. (2018). Artificial polymer materials debris characteristics along the Moroccan Mediterranean coast. Marine pollution bulletin, 128, 1-7. DOI: https://doi.org/10.1016/j.marpolbul.2017.12.067

Meira, M. (2020). 0 Estado pode proibir o uso de praias. Diário de Pernambuco. Recuperado de https://www.diariodepernambuco.com.br/ noticia/brasil/2020/04/o-estadopode-proibir-o-uso-depraias.html. Acesso em 3 jun. 2020.

Ministério da Saúde. (2020). Painel Coronavírus. Recuperado de: https://covid.saude.gov.br/. Acesso em: 12 nov. 2020.

Ministério do Turismo (2018). Estudo de demanda turística internacional. Recuperado de http://www.dadosefatos.turismo.gov.br/2016-02-04-11-54-03/demandaur\%C3\%ADstica-internacional.html. Acesso em: 17 mai. 2020. 
Moura, A. F.; \& Masquio, D. C. L. (2014). A influência da escolaridade na percepção sobre alimentos considerados saudáveis. Revista de Educação Popular, 13(1), 82-94.

OECD - Organization for economic co-operation and development (2020). Tourism trends and policies 2020.pdf. Recuperado dehttps://www.oecd-ilibrary.org/docserver/6b47b985-en. pdf? expires $=1605794645 \&$ id $=$ id $\&$ accname $=$ guest $\&$ checksum $=C 17$ C039385FB3 5253F66BD7742FEC0B4. Acesso em: 19 nov. 2020.

Organização Mundial do Turismo (2020). Turismo internacional e o Covid-19. Recuperado de https://www.unwto.org/international-tourism-and-Covid-19. Acesso em: 09 jul. 2020.

OMS/OPAS - Organização Pan-Americana da Saúde. (2020, novembro 11). Folha informativa COVID-19-Escritório da OPAS e da OMS no Brasil-OPAS/OMS | Organização Pan-Americana da Saúde. http://www.paho.org/pt/covid19

Pereira, S.A. O sentido público da praia urbana, 2016. 304 f. Tese (Tese de Doutorado em Sociologia), Universidade Federal do Sergipe, São Cristóvão, 2016. Recuperado de https://ri.ufs.br/bitstream/riufs/6236/1/SIMONE_ARAUJO_PEREIRA.pdf. Acesso em: 16 jul. 2020.

Pinsonneault, A., \& Kraemer, K. (1993). Survey research methodology in management information systems: an assessment. Journal of management information systems, 10 (2), 75-105. DOI: https://doi.org/10.1080/07421222.1993.11518001.

Polette, M. (2020). Gestão de praias no Brasil no período Pós- Covid-19: Um desafio estratégico e tático. In: Botero, C. M., Mercadé, S., Cabrera, J. A., Bombana, B. (editores). 0 turismo de sol e praia no contexto da Covid-19. Cenários e recomendações. Publicação no marco da Rede Ibero-americana de Gestão e Certificação de Praias - PROPLAYAS. Santa Marta (Colômbia), 61-63.

Prideaux, B., Thompson, M., \& Pabel, A. (2020). Lessons from COVID-19 can prepare global tourism for the economic transformation needed to combat climate change. Tourism Geographies, 22(3), 667-678. DOI: https://doi.org/10.1080/14616688.2020.1762117.

Reginato, V. D. S. C., Ribeiro, E., Meliani, P. F., Fernandez, S. de S., \& Bozio, A. F. (2020). Coleção de mapas temporais como auxílio na representação da difusão da COVID-19 no Estado de Santa Catarina: Histórico entre 12/03/2020 e 11/05/2020. Metodologias e Aprendizado, 3, 102-113.

Ritchie, J. R. B., Molinar, C. M. A., \& Frechtling, D. C. (2010). Impacts of the world recession and economic crisis on tourism: North America. Journal of Travel Research, 5-15.

Rodrigues, F. F. L., Santos, M. A. D., Teixeira, C. R. D. S., Gonela, J. T., \& Zanetti, M. L. (2012). Relación entre conocimiento, actitud, escolaridad y tiempo de enfermedad en individuos con diabetes mellitus. Acta Paulista de Enfermagem, 25(2), 284-290.

Silva, M. E. M. D. (2013). Gestão sustentável da orla marítima em destinos turísticos costeiros: a percepção dos atores sociais (Dissertação de Mestrado). Programa de Pós-Graduação em Engenharia e Gestão do Conhecimento. Florianópolis, 337p.

Souza Filho, J. R., Lins-de-Barros, F. M., \& Nunes, F. (2020). Repensando o uso das praias: a natureza pede um descanso. In: Botero, C. M., Mercadé, S., Cabrera, J. A., Bombana, B. (editores). 0 turismo de sol e praia no contexto da Covid-19. Cenários e recomendações. Publicação no marco da Rede Ibero-americana de Gestão e Certificação de Praias PROPLAYAS. Santa Marta (Colômbia), p. 66-69

Spiess, M. R. (2020). Os tempos do distanciamento social: Observações sobre novos resultados de pesquisa com estudantes. Recuperado de https://www.net-dr.org/ post/os-tempos-do-distanciamento-social-observa\%C3\%A7\%C3\%B5es-sobre-novosresultados-de-pesquisa-com-estudantes. Acesso em: 18 jul. 2020. 
Taverna, B. D., \& Mantecón, C. L. Reflexiones sobre el avance de la pandemia de COVID -19 y el ecosistema costero. Posibles consecuencias del impacto antrópico (2020). In: Botero, C.M., Mercadé, S., Cabrera, J.A., Bombana, B. (editores). 0 turismo de sol e praia no contexto da Covid-19. Cenários e recomendações. Publicação no marco da Rede Ibero-americana de Gestão e Certificação de Praias - PROPLAYAS. Santa Marta (Colômbia), 71-73.

Wang, C., Pan, R., Wan, X., Tan, Y., Xu, L., Ho, C. S., \& Ho, R. C. (2020). Immediate Psychological responses and associated factors during the initial stage of the 2019 coronavirus disease (COVID-19) Epidemic among the general population in China. Int J Environ Res Public Health. Mar 6;17(5). pii: E1729. DOI: 10.3390/ijerph17051729.

Yin, R. K. (2005). Estudos de caso: Planejamento e métodos. Bookman. Recuperado de: https://ria.ufrn.br/jspui/handle/123456789/943.

Zhang, H. W., Yu, J., Xu, H. J., Lei, Y., Pu, Z. H., Dai, W. C., ... Li, D. F. (2020). Corona Virus International Public Health Emergencies: Implications for Radiology Management. Academic Radiology, 27(4), 463-467. DOI:https://doi.org/10.1016/j.acra.2020.02.003.

Zielinski, S., \& Botero, C. M. (2020). Beach Tourism in Times of COVID-19 Pandemic: Critical Issues, Knowledge Gaps and Research Opportunities. International Journal of Environmental Research and Public Health, 17(19), 7288. DOI: https://doi.org/10.3390/ijerph17197288.

Recebido em: $31 / 07 / 2020$

Aprovado em: 09/12/2020

\section{CONTRIBUIÇÃo}

Maria Emília Martins Da Silva Garbuio: definição do problema de pesquisa e objetivos, desenvolvimento da proposição teórica, realização da revisão bibliográfica e fundamentação teórica, escolha dos procedimentos metodológicos, coleta de dados, elaboração de tabelas, gráficos e figuras, revisão crítica do manuscrito, redação e adequação às normas da RTA.

Eduardo Augusto Werneck Ribeiro: definição do problema de pesquisa e objetivos, desenvolvimento da proposição teórica, realização da revisão bibliográfica e fundamentação teórica, escolha dos procedimentos metodológicos, coleta e análise de dados, revisão crítica do manuscrito, redação e adequação às normas da RTA. 